\title{
Quantifying the appearance of jackets with adhesive interlinings
}

\author{
KyoungOk Kim ${ }^{1}$, Sho Sonehara ${ }^{2}$, Masayuki Takatera ${ }^{1 *}$ \\ ${ }^{1}$ Division of Kansei and Fashion Engineering, Institute for Fiber Engineering (IFES), Interdisciplinary Cluster for Cutting \\ Edge Research (ICCER), Faculty of Textile Science and Technology, Shinshu University, Ueda, Japan. \\ ${ }^{2}$ Faculty of Textile Science and Technology, Shinshu University, Ueda, Japan. \\ takatera@shinshu-u.ac.jp
}

\begin{abstract}
Purpose: This study quantitatively evaluates the effect of adhesive interlining on the appearance of tailored jackets with different rigidity.

Design/methodology/approach: Four tailored jackets having the same pattern and fabric and three different adhesive interlinings or no adhesive interlining were prepared as experimental samples. Criteria and characteristics for assessing jacket appearance were investigated in sensory tests. A paired comparison of the jacket appearance was conducted using a ranking method. Smoothness and constriction values were proposed and obtained using three-dimensional shape data. The smoothness value refers to the degree of wrinkling on the jacket surface and the constriction value refers to the degree of constriction of the waist line. A quantitative assessment model of jacket appearance was proposed using multiple regression analysis.
\end{abstract}

Findings: The sensory test reveals that the number of wrinkles, acceptability of wrinkling and degree of constriction of the waist are important criteria in the assessment of jacket appearance. The smoothness value for the front body and the constriction value of the waist partially agreed with the normal scores of sensory test results. Sensory evaluation values for the entire jacket appearance were estimated employing multiple regression analysis with the constriction and smoothness values. The values of jacket appearance estimated using multiple regression analysis were in good agreement with the sensory test results.

Originality/value: Criteria and characteristics to be used in the assessment of the appearance of a jacket with adhesive interlining were clarified. Employing the proposed methodology, it is possible to predict jacket appearance for different adhesive interlinings, quantitatively.

Keywords: Quantitative assessment, appearances, adhesive interlinings, tailored jacket

Paper type: Research paper

\section{Introduction}

Adhesive interlining is usually used to support the mechanical properties of the face fabric for purposes relating to garment appearance and stability. By bonding adhesive interlining, the bending rigidity and shear stiffness can be controlled. The selection of a suitable adhesive interlining is an important stage in the production of garments that are adjustable and beautiful. However, the selection depends on previous experience or laminating with actual samples, which takes time and incurs a cost. Researchers have investigated the mechanical properties of laminated fabric with adhesive interlining. Kim et al. investigated methods of predicting the bending rigidity of laminated fabrics (Kim et al., 2011; 2012; 2013a; 2013b) and the effects of adhesive mass on the shear stiffness of laminated fabrics (Kim and Takatera, 2012). Jeong et al. (2000) and Lai and Schenk (2001) proposed the optimal arrangement of adhesive interlining, yet the effects of adhesive interlining on garment appearance remain unclear. Koenig and Kadolph (1983) investigated the drape properties of several laminated fabrics with adhesive interlining focusing on the fabric drape. However, there have been no such studies on a method of evaluating the effect of adhesive interlining on the appearance of garments. Changes in the appearance of fabric are not the same as changes in the appearance of clothing. Thus, changes in the appearance of clothing need to be investigated for the appropriate selection of adhesive interlining.

Objective evaluation of clothing appearance has been investigated by many researchers. Fabric wrinkling, fabric pilling and seam pucker were considered as effective factors (Stylios, GK, 2013; Fan, J, Hunter, L and Liu, F, 2004). Researchers have evaluated garment appearance in terms of the movement of a dress or flared skirt (Matsudaira and Sugimura, 2004; Nakanishi and Niwa, 2001). Ball et al. (2001) investigated the difference between objective measurement and consumer perception of men's tailored jackets considering laminated fabric with adhesive interlining. They reported differences between measurement and perception and stated the need for a method of assessing jacket appearance, although they did not propose such a method. G. Stylios and J.O. Sotomi (1993a, 1993b) investigated aesthetic assessment of seam pucker in lightweight synthetic fabrics by measuring of seam pucker objectively with camera. They measured seam pucker of fabric strips being placed in a slot of vertical frame. Inui, S and Shibuya, A (1992) also suggested objective evaluation of seam pucker using automated contactless measurement technology. However, they did not investigated the applicability of the method for aesthetic assessment of overall clothing.

Kim et al. (2013) found that different adhesive interlinings affected the appearance of a jacket while the surface roughness was an important evaluation factor for jacket appearance. They proposed a quantitative method of evaluating the appearance of tailored jackets having different adhesive interlinings. However, the criteria with which to judge the garment 
appearance were unclear in the sensory test and they did not propose a quantitative method of evaluating specific parts of jackets. It remains necessary to investigate criteria with which to judge the garment appearance and the characteristics that determine the quality of jacket appearance.

The present study thus proposes a method of quantitatively assessing the appearance of a jacket with adhesive interlining, taking into account the criteria and characteristics of the evaluation of jacket appearance. To investigate the criteria and characteristics, sensory tests are carried out, and new quantitative assessment methods using data of three-dimensional (3D) shapes are proposed.

\section{Experimental}

\section{Experimental samples}

Four jackets made with the same pattern, the same fabric (a satin, woven fabric) and different adhesive interlinings were prepared as experimental samples as shown in Figure 1. To evaluate the small differences in jacket appearance due to differences in the adhesive interlining, a satin, woven fabric having high shear and bending rigidity was selected as the face fabric. One jacket was made without adhesive interlining (denoted "none") and the other jackets (soft-c, normal-c and hardc) had three different adhesive interlinings made from different base cloth and having different adhesive mass. To confirm the effects of the adhesive interlining only, linings were not inserted in the jackets. The jacket patterns were made for JIS 9AR size for Japanese women (Bust $83 \mathrm{~cm}$, Height $158 \mathrm{~cm}$, and Hip $91 \mathrm{~cm}$ ). The parts to which interlinings were bonded are shown in Figure 2. Specifications of the fabrics and interlinings of the jackets are given in Tables 1 and 2 . Table 3 gives the shear rigidities and bending rigidities of the samples measured using the Kawabata Evaluation System (Katotech Co. KES-FB) (Kawabata, 1980). Four jacket samples were made by an expert who has worked in the clothing field. The interlining was bonded to the face fabric using a press machine (Kobe Denki Kogyosyo, BP-V4812D) at $150{ }^{\circ} \mathrm{C}$ under $0.3 \mathrm{kgf} / \mathrm{cm}^{2} \mathrm{load}$ for a pressing time of $10 \mathrm{~s}$. Those conditions were recommended by interlining manufacturer.

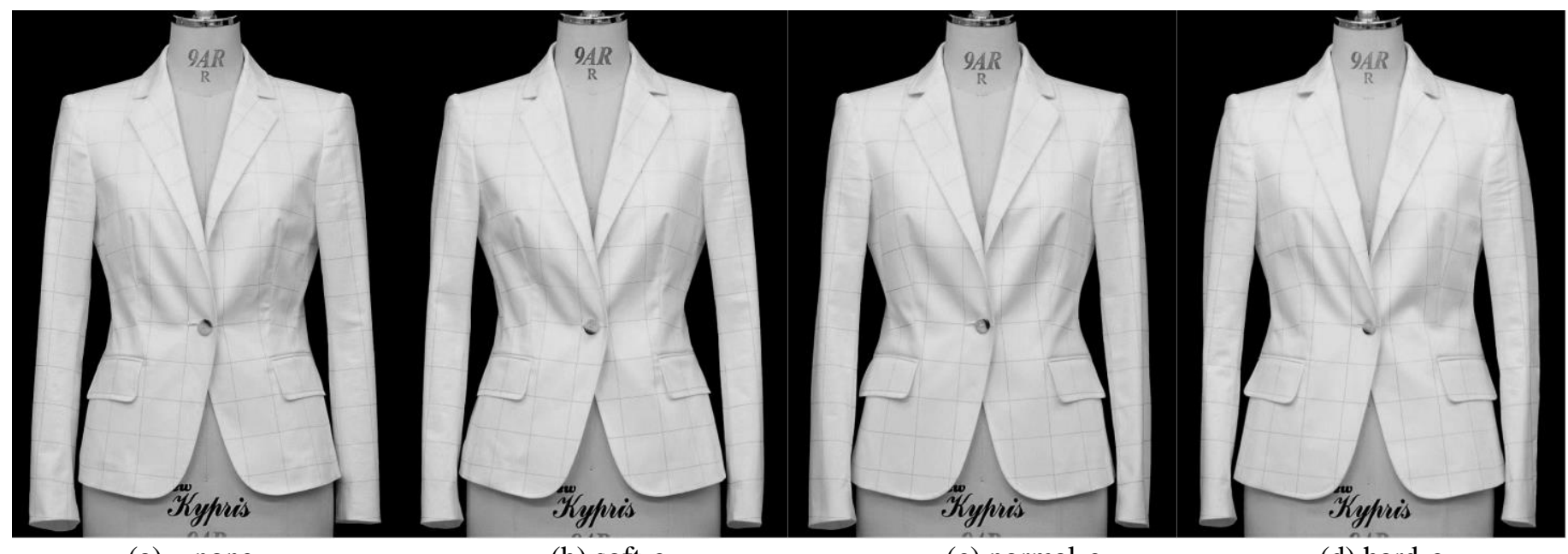

(a) none

(b) soft-c

(c) normal-c

(d) hard-c

Figure 1. Four jackets with different interlinings.

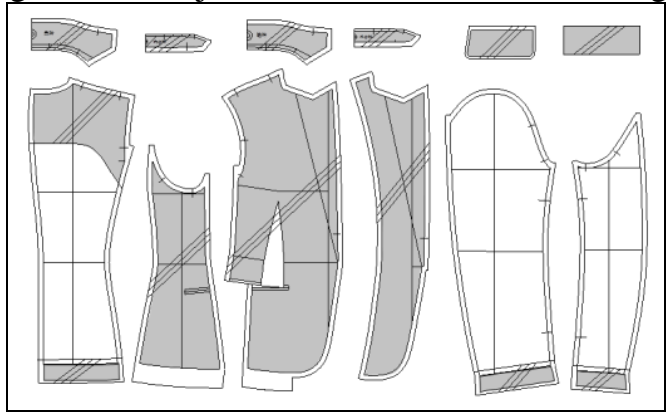

Figure 2. Jacket patterns and parts to which adhesive interlining was bonded.

Table 1. Specifications of samples

\begin{tabular}{|c|c|c|c|c|c|c|c|}
\hline \multicolumn{2}{|c|}{ Material } & Composition & Structure & Yarn count & Weave density & Mass (g/m $\left.{ }^{2}\right)$ & $\begin{array}{c}\text { Adhesive } \\
\text { mass }\end{array}$ \\
\hline \multicolumn{2}{|c|}{ Face fabric } & $\begin{array}{c}\text { Cotton 98\% } \\
\text { Polyurethane } \\
2 \%\end{array}$ & $\begin{array}{c}\text { Satin } \\
\text { (Five } \\
\text { shafts })\end{array}$ & 16tex & $99.8 \times 31.1$ & 206 \\
\hline \multirow{2}{*}{$\begin{array}{c}\text { Adhesive } \\
\text { interlining }\end{array}$} & soft & Polyester 100\% & Plain & $12 \mathrm{~d} / 12 \mathrm{f} \times 12 \mathrm{~d} / 12 \mathrm{f}$ & $40 \times 26$ & 16 & 4 \\
\cline { 2 - 9 } & normal & Polyester 100\% & Plain & $30 \mathrm{~d} / 12 \mathrm{f} \times 30 \mathrm{~d} / 12 \mathrm{f}$ & $38 \times 28$ & 39 & 8 \\
\hline
\end{tabular}


Table 2. Composition of samples

\begin{tabular}{|c|c|c|c|c|}
\hline Composition & Face fabric & Face fabric-soft & Face fabric-normal & $\begin{array}{c}\text { Face fabric- } \\
\text { hard }\end{array}$ \\
\hline Jacket reference & none & soft-c & normal-c & hard-c \\
\hline
\end{tabular}

Table 3. Shear stiffness and bending rigidity of samples

\begin{tabular}{|c|c|c|c|c|c|c|c|}
\hline \multirow{2}{*}{$\begin{array}{c}\text { Sample } \\
\text { mechanical } \\
\text { properties }\end{array}$} & \multirow{2}{*}{$\begin{array}{c}\begin{array}{c}\text { Face fabric } \\
\text { / Jacket }\end{array} \\
\begin{array}{c}\text { None } \\
\text { (warp } \times \text { weft) }\end{array}\end{array}$} & \multicolumn{3}{|c|}{ Adhesive interlining } & \multicolumn{3}{|c|}{ Jacket } \\
\hline & & $\begin{array}{c}\text { soft } \\
\text { (warp } \times \text { weft) }\end{array}$ & $\begin{array}{c}\text { normal } \\
\text { (warp } \times \text { weft) }\end{array}$ & $\begin{array}{c}\text { hard } \\
\text { (warp } \times \text { weft })\end{array}$ & $\begin{array}{c}\text { soft-c } \\
(\text { warp } \times \text { weft })\end{array}$ & $\begin{array}{c}\text { normal-c } \\
\text { (warp } \times \text { weft) }\end{array}$ & $\begin{array}{c}\text { hard-c } \\
\text { (warp } \times \text { weft) }\end{array}$ \\
\hline $\begin{array}{l}\text { Shear stiffness } \\
(\mathrm{gf} / \mathrm{cm} \cdot \text { degree })\end{array}$ & $2.338 \times 1.910$ & $0.404 \times 0.372$ & $0.524 \times 0.616$ & 0.964 & $3.254 \times 2.964$ & $3.764 \times 3.580$ & $10.348 \times 10.152$ \\
\hline $\begin{array}{c}\text { Bending rigidity } \\
\left(\mathrm{gf} \cdot \mathrm{cm}^{2} / \mathrm{cm}\right)\end{array}$ & $0.124 \times 0.078$ & $0.00145 \times 0.00056$ & $0.00956 \times 0.0066$ & $0.0248 \times 0.0265$ & $0.285 \times 0.163$ & $0.459 \times 0.216$ & $1.128 \times 0.557$ \\
\hline
\end{tabular}

\section{Sensory tests}

A sensory test was carried out to investigate the criteria with which to assess the garment appearance. Because the adhesive interlining was bonded to the face fabric partially as shown in Figure 2, different jacket parts were taken into account in the questionnaire. The four jackets were worn by four identical dummies (Kiiya Co., Ltd., 9AR, Height $158 \mathrm{~cm}$, Bust 83 $\mathrm{cm}$, Hip $91 \mathrm{~cm}$ ) at the same time in the test. The appearances of the fronts of the jackets worn by the dummies were compared for the entire jacket and for the jackets parts (Figure 3) in a paired comparison. Three male and seven female university students in their twenties, who were considered potential purchasers, participated voluntarily in the sensory test as subjects. They were not in fashion or textile major. By observing two of the four jackets from the front at the same time, a subject stated 1) which jacket had better appearance for a designated part, 2) their criteria for the judgments (with multiple answers allowed), and 3) the characteristics within the criteria (as an open response). The test was carried out in a room at a temperature of 20 $\pm 1{ }^{\circ} \mathrm{C}$ and relative humidity of $65 \% \pm 5 \%$ and under fluorescent lighting. After the evaluation, the criteria items were summarized and the responses rates of criteria items for different jacket parts were scored.

Another sensory test was carried out for jacket appearance using the criteria items that were commonly given by the subjects in the first test. In this second sensory test, the style of the middle and lower parts on the left and right of the jacket and the waist line at the front of the jacket was evaluated (see Figure 3). These parts of the jackets were selected according to the criteria obtained in the first sensory test. Thirteen male and ten female university students in their twenties, who were not involved in the first sensory test, participated in the second sensory test as subjects. The experimental environment was the same as that in the first test. The subjects observed the designated parts of the four jackets worn by dummies in a designated direction through a blind (see Figure 4) at the same time and ranked 1) the order of wrinkling, 2) the order of the degree of constriction and 3) the quality (good or bad) of the part. The subjects were not allowed to rank a designated part of two jackets equally. The subjects were not informed of the difference in the interlining. The normalizedrank method was used to obtain the normal scores for each sample.

side line, (10) sleeve cuff, (11) entire front.

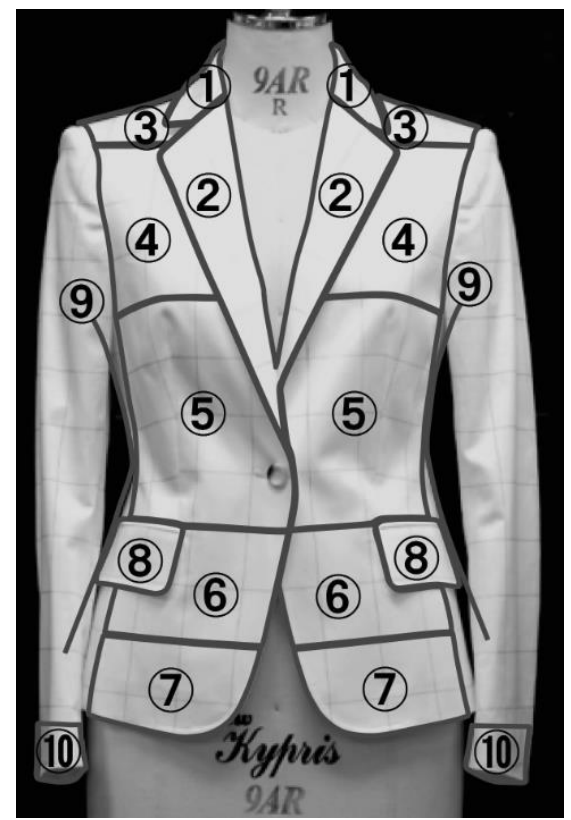

Figure 3 Parts of a jacket evaluated in the quantitative assessment of jacket appearance; (1) upper collar, (2) lower collar, (3) shoulder, (4) front body (upper), (5) front body (middle), (6) front body (lower), (7) hemline, (8) flap, (9)

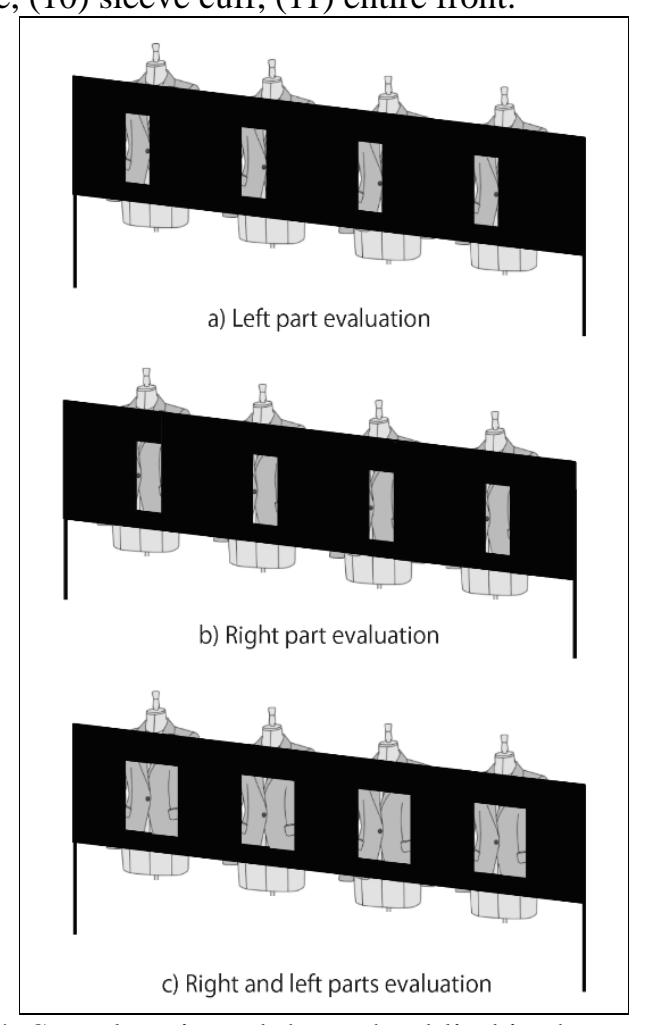

Figure 4. Samples viewed through a blind in the second 


\section{Quantitative method of assessing jacket appearance}

This study proposes a new quantitative method of assessing jacket appearance using 3D shape data. To evaluate garment appearance, measuring unevenness of surface is necessary. G. Stylios and J.O. Sotomi (1993a, 1993b) suggested aesthetic assessment method of seam pucker using image processing, they used the seam pucker frequency of vertical fabric strip as an index. Fan, J, Hunter, L and Liu, F (2004) reviewed the objective methods for assessing wrinkling, pilling and seam pucker in flat fabric by laser scanning method. However, clothing surface is made up of three dimensional shape. To assess unevenness of curved surface, the ideal shape of the garment without wrinkle is required. To avoid such problem, we used variance of curvature of a cross sections of 3D scanned data for garment as an index of the unevenness (Kim et al., 2013).

Each jacket was scanned by a 3D scanner (VIVID 700, resolution 0.6 mm, Konica Minolta Holdings, Inc., Japan) and the data were processed using software (Konica Minolta Holdings, Inc., VI-S1). The horizontal and vertical cross-section data for each jacket were extracted and compared as shown in Figure 5 (b) and (c). The horizontal cross-section curves around the hemline at the front of each sample, which had significant different sensory test results, were obtained and compared as shown in Figure 5 (b). Eleven vertical cross-section lines on the left and right hemline parts of the front of each sample were obtained and compared as shown in Figure 5 (c). The curvature and variance of curvature of the cross sections for each part were calculated. The average of the variance of curvature is referred to as the smoothness value (Kim et al., 2013) and compared with the sensory test results.

To obtain the side line that the subjects evaluated, four vertical cross-sectional lines for each $10 \mathrm{~mm}$ from the sagittal plane passing through the position of the maximum width of the horizontal waistline were obtained and superposed as shown in Figure 6 (a). The combination of the outermost point at each height was obtained from the four cross-sectional lines as shown in Figure 6 (b) and the line was considered as the waist line that subjects observed in evaluating jacket appearances. The degree of waist constriction was calculated using the vertical line $a$ and horizontal line $b$, where the length of $a$ is the distance that the side waist line is from the designated waist and hip position, and the length of $b$ is the distance from line a to the most constricted line at the waist. The degree of constriction at the waist (constriction value) was obtained by averaging the calculated degrees of constriction for the left and right parts. The obtained data were compared with the average preference of sensory test results. Comparing the results of the evaluation value and sensory evaluation, the validity of the evaluation value was investigated.

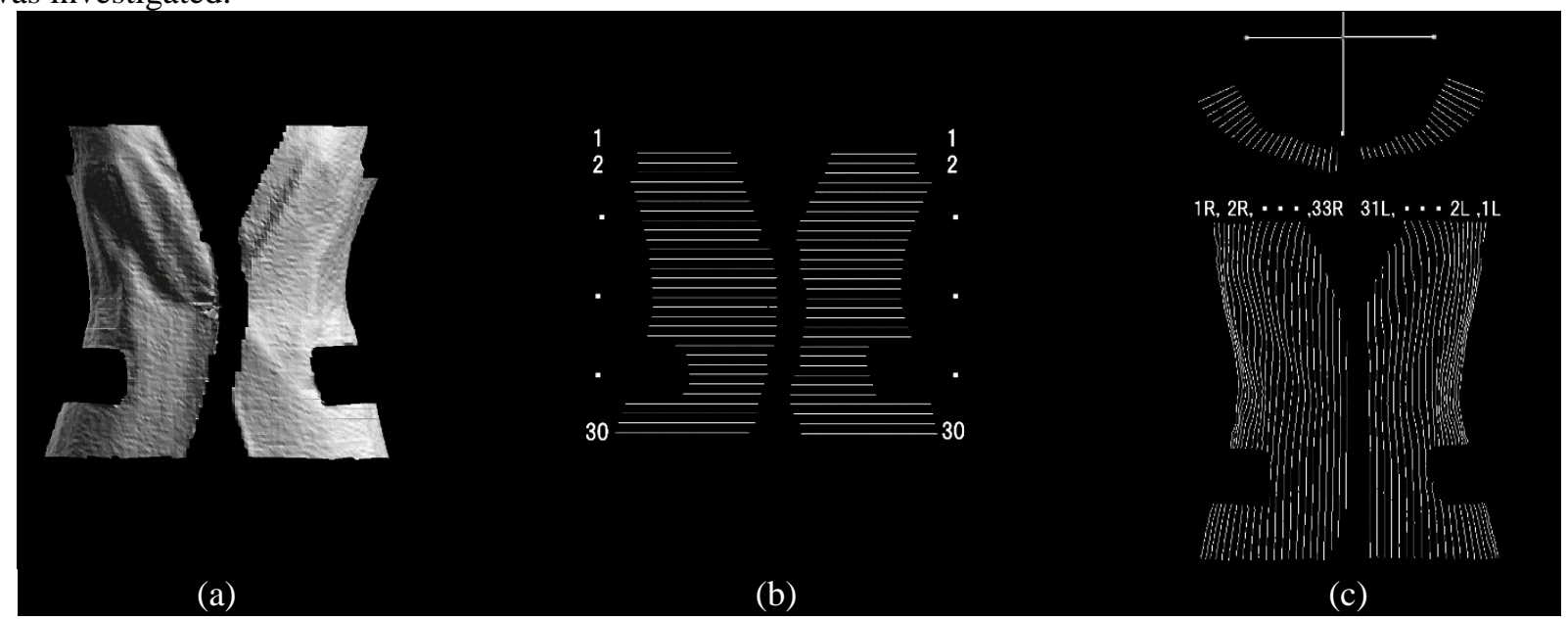

Figure 5. Example of obtained 3D data and modified data for evaluation (a) Obtained 3D data, (b) Horizontal data, (c) Vertical data.

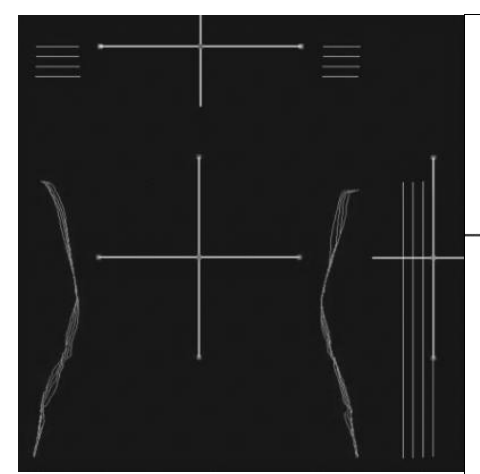

(a)

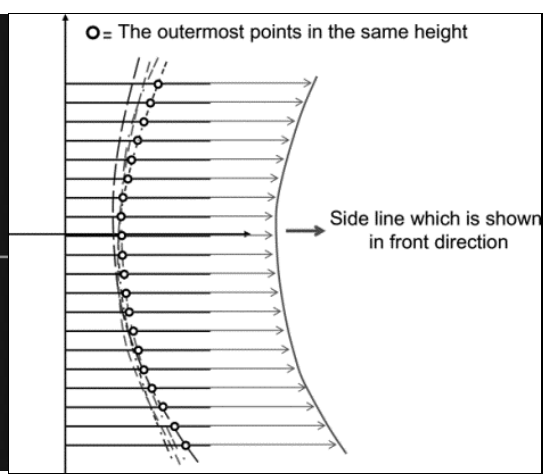

(b)

Figure 6. Visible vertical side line at the front of the jacket obtained from cross-sectional shape data

(a) Vertical data of the side line, (b) visible vertical side line. 


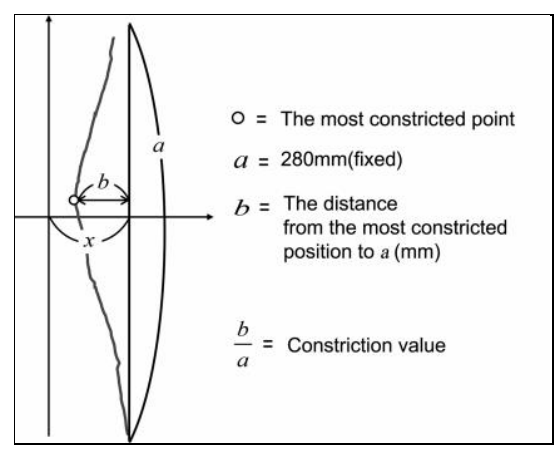

Figure 7. Method of obtaining the constriction value for the waist.

\section{Method of predicting garment appearance from the smoothness value and constriction value}

Employing multiple regression analysis with the smoothness value and waist constriction value as explanatory variables, a new equation for the prediction of garment appearance is derived:

$V=a_{1}+a_{2}$ smoothness value $+a_{3}$ constriction value,

where $a_{1}, a_{2}$, and $a_{3}$ are coefficients of the multiple regressions.

The estimated value $V$ represents the quality of garment appearance comprehensively. A higher value indicates better appearance.

\section{Results and Discussion}

\section{Criteria and characteristics for the evaluation of jacket appearance}

Table 4 presents the questionnaire results of the criteria and characteristics considered important in the quantitative assessment of jacket appearance. All nine criteria and characteristics were obtained as a result of the questionnaire. Pilling and seam pucker were not affected by difference of interlining. Table 5 gives the rates of response (i.e., the percentage of subjects who stated the criterion or characteristic) for each jacket part and the entire jacket when observed from the front. Among the characteristics, wrinkling in the front lower parts of a jacket (parts 5 and 6 in Figure 3) and waist constriction of the side line (in Figure 3 ) had response rates exceeding $70 \%$. It is thus clear that waist constriction and wrinkling were major factors when determining the quality of a jacket. Therefore, the front lower parts and waist curves of the jackets were selected for analysis in the second sensory test. Other parts of the jackets such as the collar and sleeve were neglected owing to their low response rates.

Table 4. Questionnaire results for possible criteria and characteristics to be used in the quantitative assessment of jacket appearance

\begin{tabular}{|c|c|}
\hline Criterion & Characteristics \\
\hline Wrinkling & Few wrinkles - many wrinkles \\
\hline Shape & Good looking - not good looking \\
\hline Floating from the body & Floating - not floating \\
\hline Fitting the body & Fitting - unfitting \\
\hline Symmetry & Symmetrical - unsymmetrical \\
\hline Tense & Tense - not tense \\
\hline Angulation & Angulated - not angulated \\
\hline Waist constriction & Constricted - not constricted \\
\hline $\begin{array}{c}\text { Appearance of waist } \\
\text { constriction }\end{array}$ & Good looking - not good looking \\
\hline Swelling & Swelling - not swelling \\
\hline
\end{tabular}

Table 5. Rates of responses for different jacket parts

\begin{tabular}{|c|c|c|c|c|c|c|c|c|c|c|c|}
\hline \multicolumn{2}{|c|}{ 1. Collar } & \multicolumn{2}{|c|}{ 2. Lapel } & \multicolumn{2}{|c|}{ 3. Shoulder } & \multicolumn{2}{|c|}{ 4. Front body (upper) } & \multicolumn{2}{|c|}{ 5. Front body (middle) } & \multicolumn{2}{|c|}{ 6. Front body (lower) } \\
\hline Criterion & $\begin{array}{c}\text { Respons } \\
\mathrm{e} \\
(\%)\end{array}$ & Criterion & $\begin{array}{c}\text { Respons } \\
\mathrm{e} \\
(\%)\end{array}$ & Criterion & $\begin{array}{c}\text { Respons } \\
\mathrm{e} \\
(\%)\end{array}$ & Criterion & $\begin{array}{c}\text { Respons } \\
\mathrm{e} \\
(\%)\end{array}$ & Criterion & $\begin{array}{c}\text { Respons } \\
\mathrm{e} \\
(\%)\end{array}$ & Criterion & $\begin{array}{c}\text { Respons } \\
\text { e } \\
(\%)\end{array}$ \\
\hline Wrinkling & 27 & Shape & 37 & \multirow{2}{*}{ Wrinkling } & \multirow{2}{*}{23} & Wrinklin & \multirow{2}{*}{27} & \multirow{2}{*}{ Wrinkling* } & \multirow{2}{*}{83} & \multirow{2}{*}{$\begin{array}{c}\text { Wrinklin } \\
\mathrm{g}\end{array}$} & \multirow{2}{*}{67} \\
\hline Floating & 20 & Floating & 27 & & & $\mathrm{~g}$ & & & & & \\
\hline \multirow{2}{*}{ Tension } & \multirow{2}{*}{30} & Fitting & 23 & \multirow{2}{*}{ Tension } & \multirow{2}{*}{17} & \multirow{2}{*}{ Tension } & \multirow{2}{*}{30} & \multirow{2}{*}{ Tension } & \multirow{2}{*}{37} & \multirow{2}{*}{ Tension } & \multirow{2}{*}{27} \\
\hline & & Tension & 30 & & & & & & & & \\
\hline \multicolumn{2}{|c|}{ 7. Hemline } & \multicolumn{2}{|c|}{ 8. Flap } & \multicolumn{2}{|c|}{ 9. Side line } & \multicolumn{2}{|c|}{ 10. Sleeve cuff } & \multicolumn{2}{|c|}{ 11. Entire jacket } & & \\
\hline Shape & 27 & $\begin{array}{c}\text { Wrinklin } \\
\mathrm{g}\end{array}$ & 27 & Wrinkling & 23 & Shape & 17 & Wrinkling* & 77 & & \\
\hline Tension & 20 & Floating & 27 & Shape & 20 & Tension & 17 & Shape & 60 & & \\
\hline \multirow[b]{2}{*}{$\begin{array}{c}\text { Angulatio } \\
\mathrm{n}\end{array}$} & \multirow[b]{2}{*}{30} & Fitting & 23 & \multirow{2}{*}{$\begin{array}{c}\text { Constriction } \\
*\end{array}$} & \multirow[b]{2}{*}{83} & \multirow{2}{*}{$\begin{array}{c}\text { Bilateral } \\
\text { symmetr } \\
y\end{array}$} & \multirow[b]{2}{*}{10} & Tension & 53 & & \\
\hline & & Tension & 17 & & & & & $\begin{array}{c}\text { Constrictio } \\
n\end{array}$ & 40 & & \\
\hline
\end{tabular}

* Response rate exceeding $70 \%$. 


\section{Relationship between the evaluation values and the sensory test results of jacket appearance}

Figures 8 and 9 show the obtained horizontal and vertical cross-sectional shape data for each sample of lower front body (left and right). It is seen that the amount of wrinkling differed among the four jackets in both lines. Figure 10 presents the obtained waist line data of each sample of the front body. It was confirmed that the four lines of jackets were different from each other.

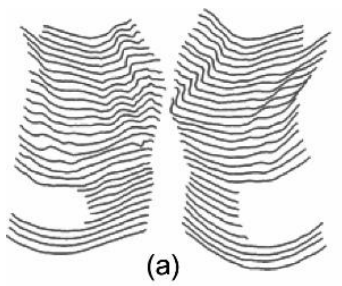

(a)

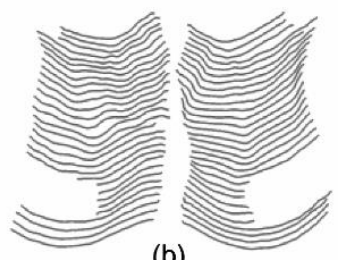

(b)

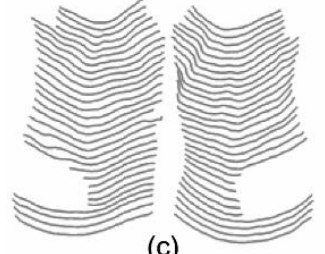

(c)

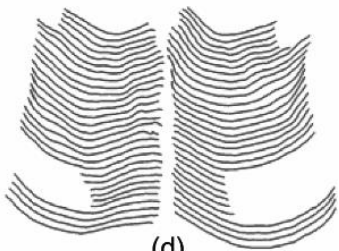

(d)

Figure 8. Obtained horizontal cross-sectional shape data for the front lower body (left and right) of each sample:

(a) none, (b) soft-c, (c) normal-c, (d) hard-c.

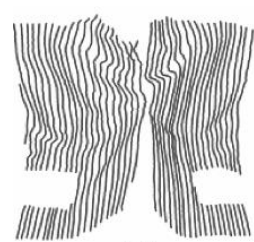

(a)

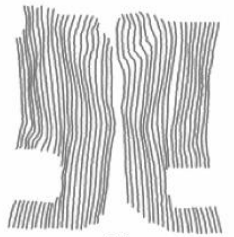

(c)

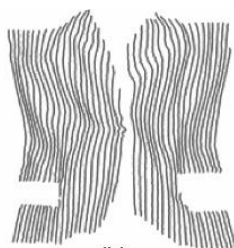

(b)

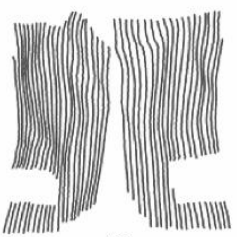

(d)
Figure 9. Obtained vertical cross-sectional shape data for the front lower body (left and right) of each sample:

(a) none, (b) soft-c, (c) normal-c, (d) hard-c.

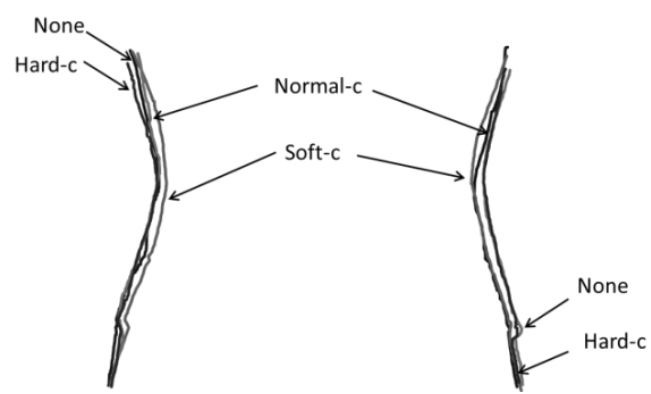

Figure 10. Obtained side line data for the front body of each sample.

Normal scores of the results obtained in the second sensory test were calculated. Figure 11 presents normal scores of the order of the number of wrinkles for each sample and Figure 12 presents normal scores of the order of the quality (i.e., acceptability) of wrinkling for each sample. The jacket without interlining had the most wrinkles and the hard-c jacket had the fewest. Wrinkling quality was highest for the normal-c jacket.

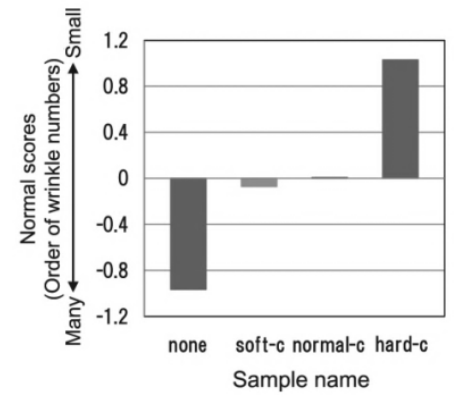

(a)

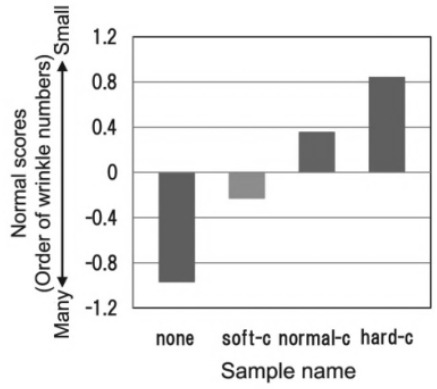

(b)

Figure 11. Normal scores of the order of the number of wrinkles for each sample:

(a) left part of the front lower body, (b) right part of the front lower body.

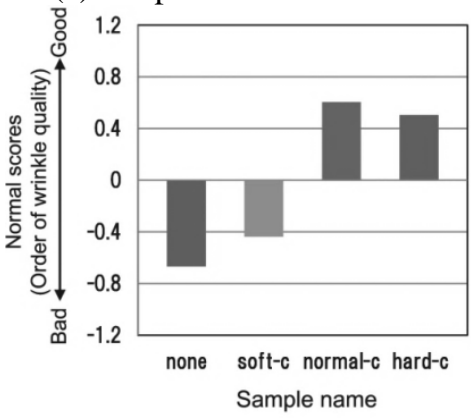

(a)

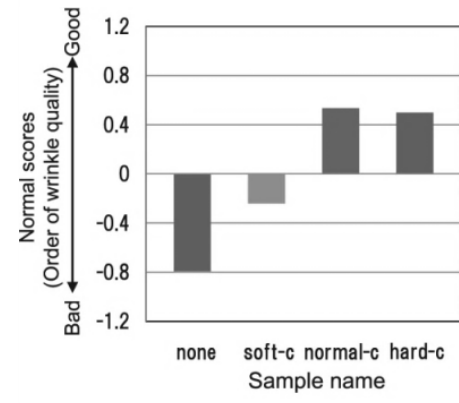

(b)

Figure 12. Normal scores of the order of wrinkling quality for each sample:

(a) left part of the front lower body, (b) right part of front lower body. 
Normal scores of the order of the degree of constriction for each sample are shown in Figure 13. The soft-c jacket was the most constricted and the hard-c jacket was the least. Normal scores of the order of the quality (i.e., acceptability) of constriction for each sample are shown in Figure 14. The constriction quality was highest for the soft-c jacket.

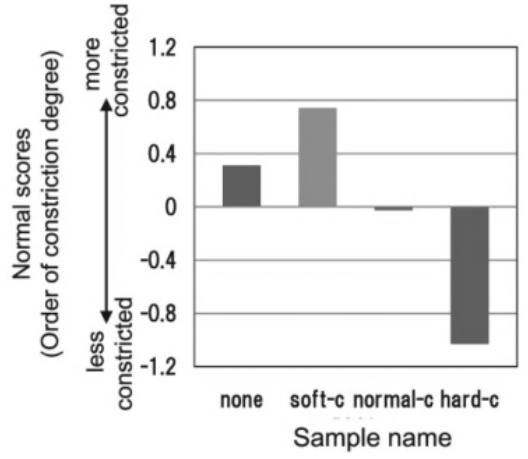

Figure 13. Normal scores of the order of the degree of constriction for each sample.

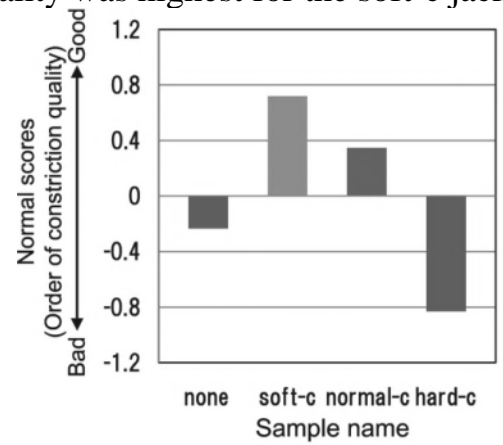

Figure 14. Normal scores of the order of quality of constriction for each sample.

Normal scores for the combination of the constriction and wrinkling of each sample are shown in Figure 15. These values show the evaluation taking into account both constriction and wrinkling. The normal-c jacket scored highest. Because the jackets perform differently in Figures 11-15, it is necessary to consider both wrinkling and waist constriction in evaluating the jacket appearance.

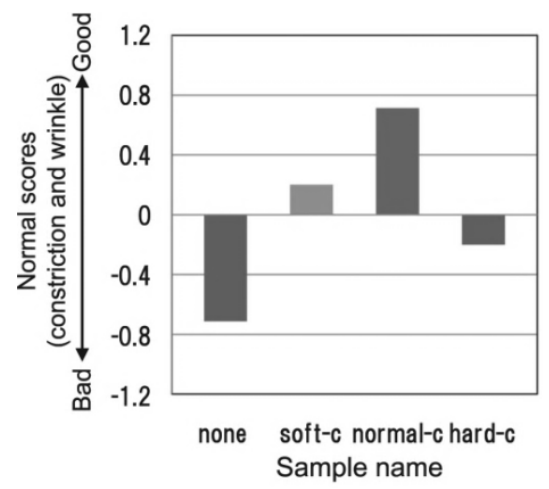

Figure 15. Normal scores considering both constriction and wrinkling of each sample.

Figure 16 shows the relationships between normal scores of the order of the number of wrinkles and horizontal smoothness values for the front body. Figures 16 (a) and (b) respectively present the relationships for the left and right sides of the jackets, and Figure 16 (c) gives the mean relationship for the two sides.

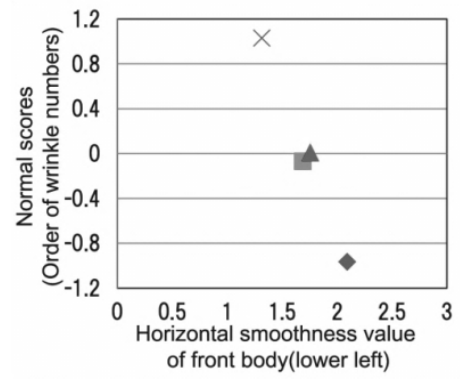

(a)

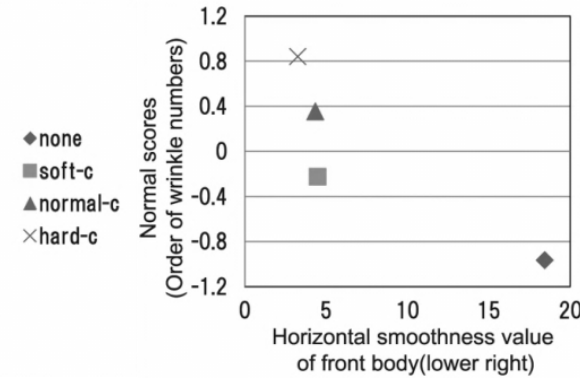

(b)

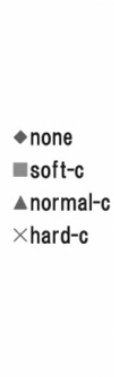

Figure 16. Relationship between normal scores of the order of the number of wrinkles and horizontal smoothness values of the front body: (a) lower left, (b) lower right, and (c) mean of left and right.

Figure 17 shows the relationship between normal scores of the order of the number of wrinkles and vertical smoothness values of the front body. Figures 17 (a) and (b) respectively present the relationships for the left and right sides of the jackets, and Figure 17 (c) gives the mean relationship for the two sides. The reason of difference between left and right was the button. The left side has a button and the right side has a button hole. The fabric on right side was pulled intensively than one on left side. The relations, especially the relation for the lower left parts of the jackets, are linear. However, even though the linear results suggest the possibility of evaluating garment appearance, the linear relationships disagree. 


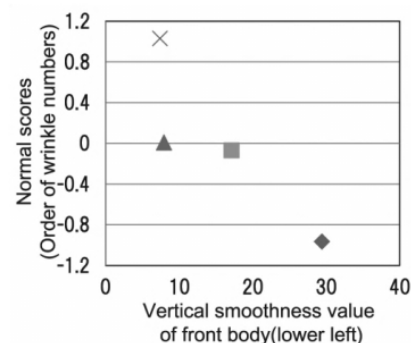

(a)

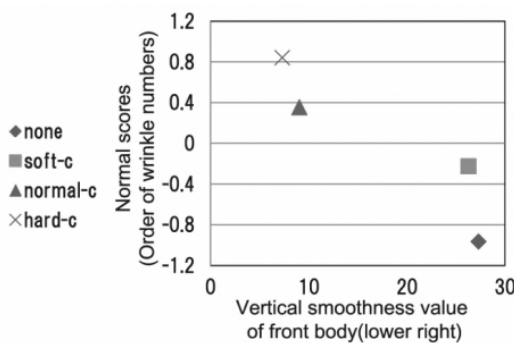

(b)

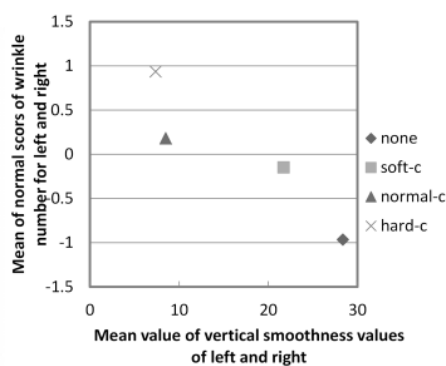

(c)

Figure 17. Relationship between normal scores of the order of the number of wrinkles and vertical smoothness values of the front body: (a) lower left, (b) lower right, and (c) mean of left and right.

Figure 18 shows the relationship between normal scores of the order of the constriction of the waist line and constriction value of the waist line. As shown in Figure 18, normal scores of the order of the constriction of the waist line and constriction value have a linear relationship, even though the differences among jackets are small.

It was thus found that the constriction and smoothness values are effective in evaluating the quality of jacket appearance.

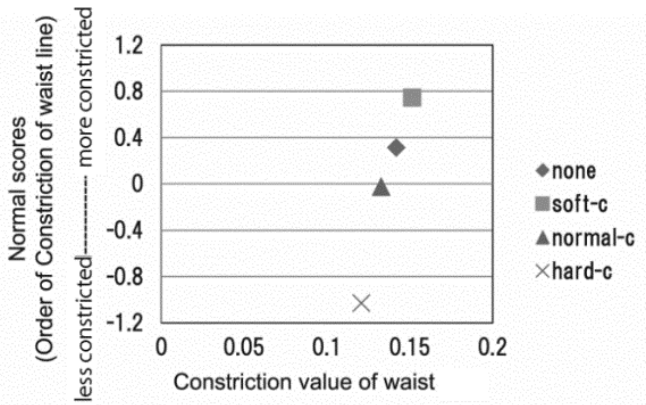

Figure 18. Relationship between normal scores of the order of constriction of the waist line and the constriction value of the waist line.

\section{Equation for predicting the evaluation of jacket appearance}

As previously mentioned, the smoothness value for the front body and the waist constriction value are in good agreement with the normal scores obtained in sensory tests. It is thus clear that wrinkling and the waist constriction are important characteristics in the assessment of jacket appearance. However, it remains difficult to evaluate jacket appearance taking into account both constriction and wrinkling. The tendencies of wrinkling and constriction obtained from the sensory test were different; i.e., the two differently affect the evaluation of jackets. Thus, a new method is needed to evaluate jacket appearance, taking into account the two characteristics together. We thus proposed a new prediction equation (1) with which to assess the jacket appearance using multiple regression analysis with two explanatory variables, the waist constriction value and smoothness value.

In the sensory test, we measured the vertical and horizontal smoothness values for left and right parts. Each value was in agreement with the normal scores, partially. Thus, the values were separately considered as the explanatory variable in multiple regression analysis. In the sensory test for the overall jacket appearance, we used values that were obtained for both the left and right of each jacket. Thus, for the horizontal and vertical smoothness values, the means for the left and right were used.

Equation (2) is the regression equation obtained using constriction and horizontal smoothness values as explanatory variables. Figure 19 (a) is a plot of evaluation value $V$ and the results of the sensory test taking into account both the constriction and horizontal smoothness values. Even though $\mathrm{R}^{2}$ has a high value of 0.82 , the estimation results for the normal$\mathrm{c}$ jacket are not in good agreement with the results of the sensory test. Furthermore, Akaike's information criterion value (AIC), for which a lower value indicates a better model, is -6.02 .

$$
\mathrm{V}=7.2582+1.9664 \times \text { horizontal smoothness value }-54.0797 \times \text { constriction value }
$$

Equation (3) is the regression equation obtained using constriction and vertical smoothness values. The plotted results of the estimation and the sensory test are shown in Figure 19 (b). In the equation, the effect of the vertical smoothness values is excluded because it is negligible in size. The plotted results also show disagreement with the sensory test results. The AIC value is -1.81 .

$$
V=2.4369-17.8266 \times \text { constriction value }
$$

Regression equation (4) is obtained using the mean of the vertical and horizontal smoothness values. Figure 19 (c) shows the plotted results of the estimation and sensory test. The figure shows high correlation $\left(R^{2}=0.97\right)$ and good agreement with the sensory test results. The quality of jacket appearance can thus be predicted using both vertical and horizontal smoothness values and the constriction value. Consequently, the proposed characteristic values are effective for the assessment 
of appearance of a jacket with adhesive interlining. The AIC is -14.15 , which was the smallest value among the three models. Equation (4) is thus the best model.

$V=-11.2443-0.2461 \times$ smoothness value $+101.3073 \times$ constriction value

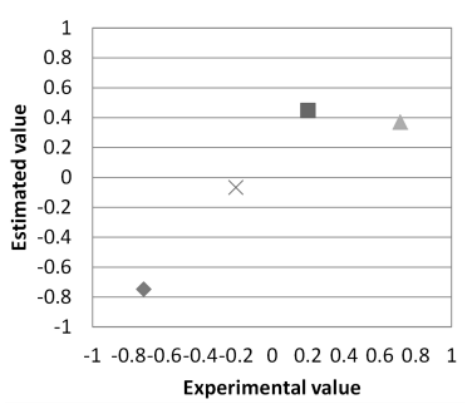

(a)
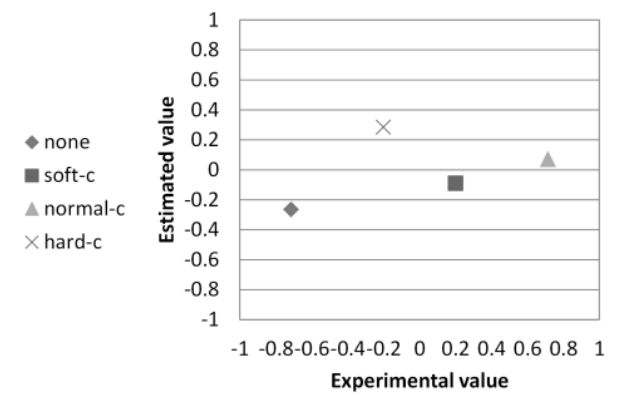

(b)

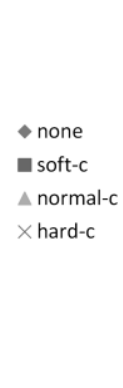

Figure 19. Relationships between evaluation value $V$ and normal scores taking into account both wrinkling and waist constriction of each sample: (a) horizontal smoothness values for the left and right sides of a jacket $\left(R^{2}=0.82\right)$, (b) vertical smoothness values for the left and right sides of a jacket $\left(R^{2}=0.15\right)$, (c) horizontal and vertical smoothness values for the left and right sides of a jacket $\left(R^{2}=0.97\right)$.

\section{Conclusion}

A quantitative method of assessing the appearance of a jacket with adhesive interlining was proposed. It was found that wrinkling and waist constriction are important characteristics in the assessment of jacket appearance. The vertical and horizontal smoothness values for the front of the jacket and the constriction values for the waist were obtained from 3D data to predict the quantitative evaluation of jacket appearance. The values partially agreed with sensory test results.

An equation for predicting jacket appearance using both the smoothness value and constriction value was proposed. The estimated value had high correlation with the results of the sensory test that considered the constriction value and vertical and horizontal smoothness values. The proposed values are thus effective in the assessment of the appearance of a jacket with adhesive interlining. The proposed characteristics and methodology can be used to predict jacket appearance quantitatively.

\section{References}

Ball, C., Fairclough, D. and Ruckman, J.E. (2001), "Men's tailored jackets: objective measurement and consumer perception", Journal of Fashion Marketing and Management, Vol. 5, No. 3, pp. 189-198.

Jeong, S.H., Kim, J.H. and Hong, C.J. (2000), "Selecting optimal interlinings with a neural network", Textile Research Journal, Vol. 70, No. 11, pp. 1005-1010.

Kim, K.O., Inui, S. and Takatera, M. (2011), "Verification of prediction for bending rigidity of woven fabric laminated with interlining by adhesive bonding", Textile Research Journal, Vol. 81, No. 6, pp. 598-607.

Kim, K.O., Inui, S. and Takatera, M. (2012), "Prediction of bending rigidity for laminated fabric with adhesive interlining by a laminate model considering tensile and in-plane compressive moduli", Textile Research Journal, Vol. 82, No. 4, pp. 385399.

Kim, K.O., Inui, S. and Takatera, M. (2013a), "Bending rigidity of laminated fabric taking into account the neutral axes of components", Textile Research Journal, Vol. 83, No. 2, pp. 160-170.

Kim, K.O., Inui, S. and Takatera, M. (2013b), "Prediction of bending rigidity for laminated weft knitted fabric with adhesive interlining", Textile Research Journal, Published online before print March 8, doi: 10.1177/0040517513478453.

Kim, K.O. and Takatera, M. (2012), "Effects of adhesive agent on shear stillness of fabrics bonded with adhesive interlining", Journal Fiber Bioengineering and Informatics, Vol. 5, No. 2, pp. 151-162.

Kim, K.O., Sonehara, S. and Takatera, M. (2013), "Quantitative assessment of jackets appearances with bonding adhesive interlinings using two-dimensional and three-dimensional analysis", International Journal of Affective Engineering, Vol. 12, No. 2, pp. 177-183.

Koenig, S.K. and Kadolph, S.J. (1983), "Comparison of performance characteristics of seven fusible interfacings", Textile Research Journal, Vol. 53, No. 6, pp. 341-346.

Kohn, I.L. and Ashdown, S.P. (1998), "Using video capture and image analysis to quantify apparel fit", Textile Research Journal, Vol. 68, No. 1, pp. 17-26.

Lai, S.S. and Schenk, A. (2001), "Optimal combinations of face and fusible interlining fabrics", International Journal of Clothing Science and Technology, Vol. 13, No. 5, pp. 322-338.

Matsudaira, M. and Sugimura, M. (2004), "objective evaluation equation for the appearance of swinging flared skirts", Textile Research Journal, Vol. 74, pp. 1007.

Nakanishi, M. and Niwa, M. (2001), "Fabric mechanical parameters related to the beauty of fabric movement of ladies's garments brought about by human motion", J. Home. Econ. Jpn, Vol. 52, No. 3, pp. 251-264.

Silvestre-Blanes, J., Berenguer-Sebastiá, J., Pérez-Lloréns, R., Miralles, I. and Moreno, J. (2011), "Garment smoothness appearance evaluation through computer vision”, Textile Research Journal, published online 19 October 2011. 
Kawabata S. (1980), "The Standardization and Analysis of Hand Evaluation, 2nd ed. “, Textile Machinery Society of Japan, Osaka.

Stylios G and Sotomi J O (1993a), "Investigation of Seam Pucker as an Aesthetic Property Using Computer Vision", Part 1, A Cognitive Model for the Measurement of Seam Pucker, Journal of the Textile Institute, Vol. 84, No.4, pp. 593-600.

Stylios G and Sotomi J O (1993b), "Investigation of Seam Pucker as an Aesthetic Property Using Computer Vision", Part 2, Model Implementation using Computer Vision, Journal of the Textile Institute, Vol. 84, No.4. pp. 601-610

Inui, S and Shibuya, A (1992), "Objective Evaluation of Seam Pucker: using automated contactless measurement technology." International Journal of Clothing Science and Technology Vol. 4, No.5, pp. 24-33.

Stylios, GK, 2013, "The appearance of seams in non-iron shirts" in Joining Textiles: Principles and Applications. Jones, I. \& Stylios, G. K. (eds.). UK: Woodhead Publishing Ltd., pp.467-476Fan, J, Hunter, L and Liu, F (2004), "Objective evaluation of clothing appearance" in Clothing appearance and fit: Science and technology. Fan, J, Yu, W and Hunter, L. (eds.). Elsevier, pp.43-71. 